\title{
The Influence of Age, Shoe Type and Kicking Direction on the Severity of Head Trauma
}

\section{Penzkofer $^{1^{*}}$, Barnsteiner $\mathbf{K}^{2}$ and Dendorfer $\mathbf{S}^{1}$}

${ }^{1}$ Laboratory for Biomechanics, University of Applied Sciences Regensburg, Regensburg Center of Biomedical Engineering, Regensburg, Germany

${ }^{2} B M W$ AG, Car safety, Munich, Germany

"Corresponding author: Penzkofer R, Laboratory for Biomechanics, University of Applied Sciences, Regensburg Center of Biomedical Engineering, Josef-Engert-Str. 9, 93053 Regensburg / Germany, Tel: (0941) 943-5199; Fax: (0941) 943-1428; E-mail: rainer.penzkofer@hs-regensburg.de

Received date: Jul 24, 2013; Accepted date: Dec 23, 2013; Published date: Jan 08, 2014

Copyright: ( 2014 Penzkofer et al. This is an open-access article distributed under the terms of the Creative Commons Attribution License, which permits unrestricted use, distribution, and reproduction in any medium, provided the original author and source are credited.

\begin{abstract}
In the last few years, increasingly kicks to the head were observed as a criminal offense. This study examined the influence of age, shoe type and kicking direction on the severity of head trauma.

Male test persons were divided into two groups "Old" and "Young". Both groups were equipped with light sneakers and combat boots. A standard laboratory crash dummy was used to simulate the victim's body. First, the dummy's head, free floating above the ground, was kicked vertically. Second, the dummy's head was kicked horizontally. Established injury criteria were used to quantify the injury risk.
\end{abstract}

No influence concerning the type of foot wear and no difference between the groups "Old" and "Young" could be found. For all analyses, kicking vertically generally lead to a higher risk for the subject compared to kicking horizontally.

In this study, only the integral effect of the kicks could be analyzed. A detailed injury pattern cannot directly be derived from the data. Nevertheless, the presented data show the massive potential of injuries associated with head kicks.

Keywords: Head trauma; Biomechanics; Kicks

\section{Introduction}

In the recent past, violent crimes in which the offender attacked the victim brutally with targeted kicks to the head were subject of regional and national coverage in several cases and therefore the focus of public interest.

Between the years 2008 and 2012, 5399 offences of grievous bodily harm were recorded in the city of Nuremberg. In 119 cases purposeful kicks to the head were observed [1].

Attacks of this form regularly follow a characteristic pattern. First, the victim is attacked and brought to the ground by the perpetrators. During this action blunt force is applied, usually strokes. After that, the perpetrator(s) kick the victim [2].

$93.8 \%$ of the offenders were male. As far as female suspects were involved, these acted mainly together with male suspects. By far, the largest number of suspects was between 21 and 30 years old, followed by 11 to 20 years olds. On average the offenders were 30.3 years old [3].

According to the load application point, in many cases severe injuries are caused by kicks to the human head, resulting in a perilous and deathly outcome for the victims. Mostly, these injuries are the result of two different damage mechanisms:

On the one hand, due to the direct impact by deformation of the bone structure, the kicks lead to fractures of the skullcap, the base of the skull, the facial bones and the mandible and on the other hand caused by movements of the encephalon relative to the inside of the skull and the tissue structures as a result of acceleration. This may cause bleeding due to a rupture of the bridging veins. Furthermore, reversible injuries like comotio cerebri and soft tissue injuries are possible [4-6].

In the context of a kick to the human head it can be assumed, that the force application point does not necessarily match the center of gravity, which implicates a linear as well as rotational acceleration of the head [7]. The severity of injuries is currently classified with the help of injury scales like for instance the AIS (Abbreviated Injury Scale) [8]. Based on biomechanical studies, different scores like HIC (Head Injury Criterion) try to correlate the severity of head injuries with physical parameters like acceleration and acting forces.

In order to study the biomechanics of these injury mechanisms and to investigate the mechanical physical parameters an experimental study implying human bodies was performed in 1986. The load was applied using a standardized impact testing machine [7].

In a further study conducted by Glißmann et al. [7] a crash test dummy used by the automobile industry for improving car safety was positioned lying on its side and head as well as thorax were kicked. Alongside horizontal kicks, in reality often kicks from the prior vertical to the victim's head are observed, which were not studied biomechanically up to now. Furthermore, there are no studies that correlate the biomechanical results with established injury scores and scales. 


\section{Purpose (Hypothesis)}

The aim of this study was to examine the influence of age, shoe type and kicking direction on the severity of head trauma based on established injury risk criteria.

\section{Materials and Methods}

\section{Population}

The test persons playing the offenders were divided into two groups:

"Young": (20 to 36 years; $28.2 \pm 5.8$ years). This group contained persons showing a well-trained condition (e.g. martial arts) with a body weight from 68 to $98 \mathrm{~kg}(84.8 \mathrm{~kg} \pm 8.1 \mathrm{~kg})$. The body height of these probands ranged from $175 \mathrm{~cm}$ to $193 \mathrm{~cm}(186 \mathrm{~cm} \pm 7.4 \mathrm{~cm})$.

"Old": ( 37 to 56 years; $49.6 \pm 6.0$ years). The test persons in this group showed an average or untrained physique with a body weight ranging from $72 \mathrm{~kg}$ to $98 \mathrm{~kg}(86.1 \pm 7.6 \mathrm{~kg})$. The person's size was 175 $\mathrm{cm}$ to $190 \mathrm{~cm}(181.8 \mathrm{~cm} \pm 4.2 \mathrm{~cm})$.

13 test persons were included in the group "Young" and 14 in the group "Old". Only male probands participated in this study.

All test persons were members of German police tactical units or the regular German police. Some of them learned special combat and self-defense techniques during their training.

\section{Foot wear}

Two different kinds of footwear were used in this study to investigate their influence on the measurable forces and the acceleration behavior of the human body (head).

On the one hand, an arbitrary model of light and soft sneakers (LS) and on the other hand a model of hard combat boots (CB) with a high bootleg were employed.

Both groups ("Young" and "Old") used both kinds of shoes.

\section{Measurement Technique}

To capture the acting forces and accelerations in the human head area, a crash-dummy in human form (WorldSID, Humanetics, and Plymouth, Michigan, USA) was used. This kind of dummy is also applied for evaluating the vehicle safety and for estimating the risk of injury to the human body. The sensor systems were arranged as follows:

\section{Dummy head} $\left.\mathrm{s}^{2}\right)$.

Tri-axial translational accelerations in the center of gravity (in $\mathrm{m} /$

Tri-axial rotational angular velocity (in deg/s).

The data logging of the above mentioned parameters was performed by means of a digital data logging unit (Kistler MiniDau KT 3700 advanced, Winterthur, Switzerland) using a sample rate of 10 $\mathrm{kHz}$ and a resolution of 15 bit. The frequency bandwidth after the filtering process was $1 \mathrm{kHz}$.

The coordinate system of the dummy was used according to the sign conventions for crash test measurements (SAE Safety Test Instrumentation Standards Committee) (Figure 1).

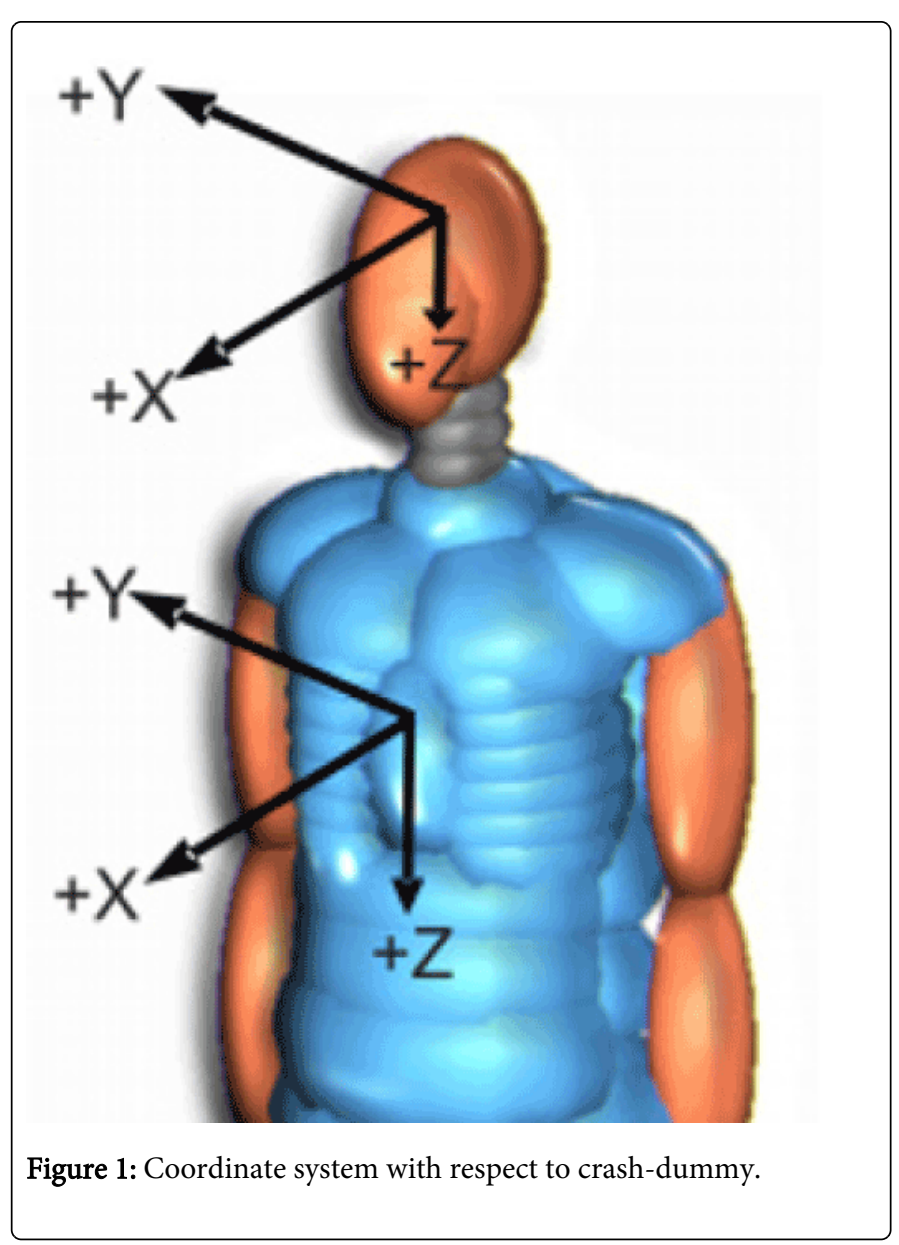

Contact forces between the dummy's head and the ground were measured as a function of time using a custom-made force rig including four uniaxial load cells (IF-600, Humanetics Innovative Solutions Plymouth, USA) between two rigid aluminium plates (BMW AG, Munich, Germany).

\section{Test procedure}

\section{Vertical kick test with combat boots (VKT CB) (Figure 2):}

During the first test series, the dummy was positioned lying on its side. To capture the contact force during the head hitting the ground, the force rig was placed between the head and the ground. Because of the dummy neck's stiffness, the head was in a free-floating position about $80 \mathrm{~mm}$ above the force rig prior to testing. Before kicking, the test person standing on two legs was positioned on a wooden platform to compensate the height difference of the ground to the upper level of the force rig. The dummy's head was loaded in vertical direction ( $\mathrm{x}$ axis) by the sole of the test person's shoe resulting in a contact between the opposite side of head and top surface of force rig. This test series was carried out by both groups (Young, Old) using combat boots (CB). 
Citation: Penzkofer, Barnsteiner K, Dendorfer S (2014) The Influence of Age, Shoe Type and Kicking Direction on the Severity of Head Trauma.

Page 3 of 5

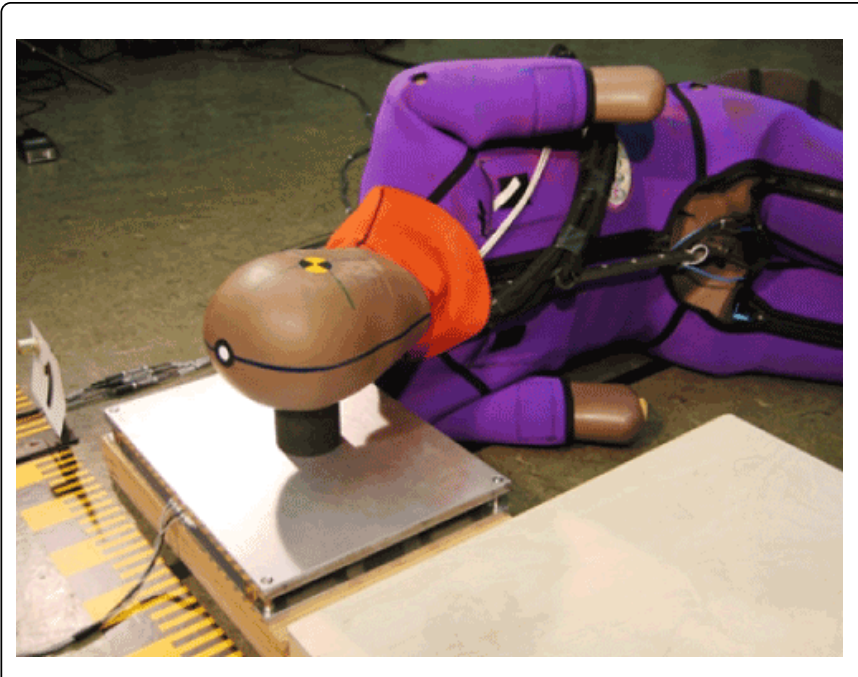

Figure 2: Study Part A: Set up for vertical kick test: Crash-dummy was lying on its side; a spacer between the dummy head and the force rig was used to position the head and was removed prior to testing.

\section{Horizontal kick test with light sneakers (HKT LS) (Figure 3):}

In this case, the dummy was placed in a supine position. The occiput was lying on the ground. The probands could choose between kicking with the tip of the shoe or with the instep (sole). The test person was standing next to the dummy and performed a single kick laterally (y-axis) to its head without taking a run-up. As in the first test series the occurring accelerations were measured in the dummy head. This part of the study was performed by both groups (Young, Old) wearing light sneakers (LS).

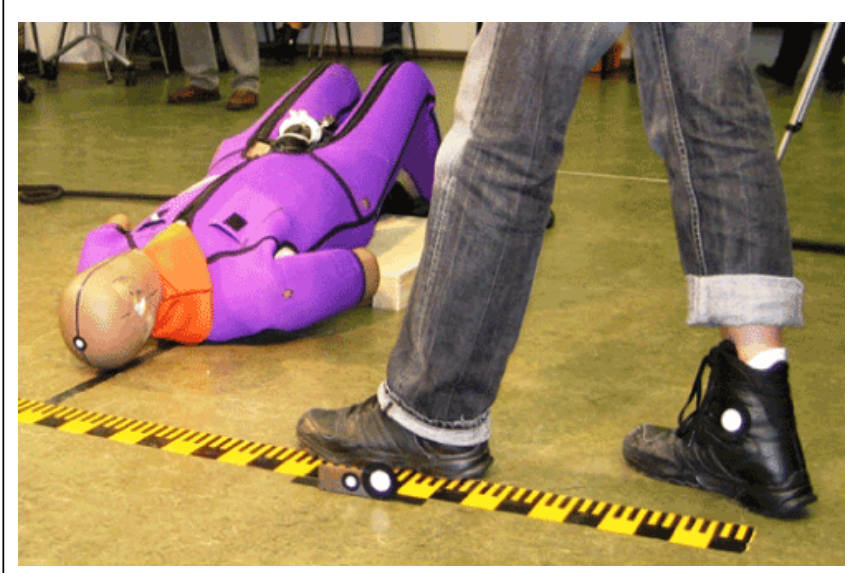

Figure 3: Study Part B/C: Set up for horizontal kick test: the crashdummy was lying in supine position, while the kick was performed laterally to the body.

\section{Horizontal kick test with combat boots (HKT CB):}

This part (C) directly corresponded to study part (B). Unlike part B instead of light sneakers (LS) combat boots (CB) were worn by both groups (Young, Old).

\section{Data processing}

Well established injury criteria and literature data for forces and accelerations were used in order to quantify the injury risk which results from the impact.

Head Impact Criteria (HIC) has been used to analyze the translational accelerations [9]. HIC is computed according to the equation:

$$
\mathrm{HIC}=\max \left[\frac{1}{\mathrm{t}_{2}-\mathrm{t} 1} \int_{\mathrm{t}_{1}}^{\mathrm{t}_{2}} \mathrm{a}(t) d t\right] \quad\left(t_{2}-t_{1}\right)
$$

t1, t2: discrete time points

$\mathrm{a}(\mathrm{t})$ : translatoric acceleration

A HIC value of 1000 is often used as upper bound for car safety investigations.

Rotational acceleration has been analyzed by comparing maximum achieved rotational acceleration with severity bounds for injuries.

To study the effects of combined translational and rotational accelerations the GAMBIT (Generalized Acceleration Model for Brain Injury Threshold) has been employed [8]. A GAMBIT of 1.0 was determined to represent a $50 \%$ probability for irreversible head injuries [10]. The GAMBIT is computed as following:

$G A M B I T=\left[\left(\frac{a(t)}{a_{\mathcal{C}}}\right)^{\mathrm{n}}+\left(\frac{\varphi(t)}{\varphi_{\mathcal{C}}}\right)^{m}\right]^{\frac{1}{k}}$

: rotational acceleration

$\mathrm{m}, \mathrm{k}$ : constants

These criteria are well established and especially the HIC is heavily used in the automotive sector assessing car safety.

Furthermore the theoretical, equivalent fall height (EFH) which is necessary to achieve an equivalent acceleration, as it has been achieved by the kicks, has been computed according to:

$$
h=\frac{v^{2}}{2 * g}
$$

v: velocity

\section{g: gravitational acceleration}

The injury criteria used allow for an investigation of the integral injury risk- / severity but are not valid for detailed analyses of injury patterns.

\section{Results}

Table 1 displays the range of results for the different criteria showing the results for the groups Young and Old.

There was no significant difference between the HKT CB and the HKT LS group. Also no significant difference was found by analyzing the criteria "age" and "combat background" (not shown in detail). Therefore, only two groups have been analyzed and compared: HKT and VKT, neglecting the influences of age, combat background and shoe type. 
Citation: Penzkofer, Barnsteiner K, Dendorfer S (2014) The Influence of Age, Shoe Type and Kicking Direction on the Severity of Head Trauma.

Page 4 of 5

To analyze the potentially possible range of injuries minimum and maximum values of the two groups are used for further evaluations.

Rotational acceleration has been found ranging from 2720 to 6770 $\mathrm{rad} / \mathrm{s}^{2}$ and from 2670 to $9160 \mathrm{rad} / \mathrm{s}^{2}$ in the groups VKT and HKT respectively. According to the work of Gennarelli et al. [8] (Table 2), this would lead to injuries ranging from an AIS level 2 for VKT to an AIS level of 3 for HKT.

\begin{tabular}{|c|c|c|c|c|c|c|c|}
\hline & \multirow[t]{2}{*}{ Units } & \multicolumn{2}{|l|}{ VKT CB } & \multicolumn{2}{|l|}{ HKT LS } & \multicolumn{2}{|l|}{ HKT CB } \\
\hline & & Young & Old & Young & Old & Young & Old \\
\hline $\begin{array}{l}\text { Equivalent fall } \\
\text { height }\end{array}$ & {$[\mathrm{m}]$} & $\begin{array}{l}19.0 \pm 6.3 \\
10.7-32.1\end{array}$ & $\begin{array}{l}16.5 \pm 4.6 \\
10.3-27.0\end{array}$ & $\begin{array}{l}7.8 \pm 2.5 \\
2.4-11.9\end{array}$ & $\begin{array}{l}7.5 \pm 1.7 \\
4.5-10.3\end{array}$ & $\begin{array}{l}8.1 \pm 4.2 \\
0.5-14.7\end{array}$ & $\begin{array}{l}7.1 \pm 3 \\
2.5-13.3\end{array}$ \\
\hline HIC & {$[-]$} & $\begin{array}{l}1758 \pm 842 \\
725-3746\end{array}$ & $\begin{array}{l}1378 \pm 570 \\
635-2770\end{array}$ & $\begin{array}{l}157 \pm 115 \\
48-415\end{array}$ & $\begin{array}{l}157 \pm 89 \\
32-329\end{array}$ & $\begin{array}{l}130 \pm 114 \\
15-436\end{array}$ & $\begin{array}{l}126 \pm 137 \\
22-554\end{array}$ \\
\hline GAMBIT & {$[-]$} & $\begin{array}{l}1.28 \pm 0.36 \\
0.74-2.02\end{array}$ & $\begin{array}{l}1.06 \pm 0.24 \\
0.68-1.62\end{array}$ & $\begin{array}{l}0.37 \pm 0.13 \\
0.24-0.66\end{array}$ & $\begin{array}{l}0.34 \pm 0.10 \\
0.17-0.52\end{array}$ & $\begin{array}{l}0.31 \pm 0.14 \\
0.15-0.68\end{array}$ & $\begin{array}{l}0.30 \pm 0.14 \\
0.17-0.75\end{array}$ \\
\hline max. Acc. & [g] & $\begin{array}{l}320 \pm 90 \\
183-504\end{array}$ & $\begin{array}{l}265 \pm 60 \\
169-404\end{array}$ & $\begin{array}{l}86 \pm 34 \\
47-164\end{array}$ & $\begin{array}{l}81 \pm 27 \\
35-128\end{array}$ & $\begin{array}{l}75 \pm 36 \\
33-170\end{array}$ & $\begin{array}{l}73 \pm 37 \\
39-187\end{array}$ \\
\hline max. rot. acc. & {$\left[\mathrm{rad} / \mathrm{s}^{2}\right]$} & $\begin{array}{l}4690 \pm 1320 \\
2720-6770\end{array}$ & $\begin{array}{l}4630 \pm 990 \\
2720-6290\end{array}$ & $\begin{array}{l}6030 \pm 1650 \\
4250-9160\end{array}$ & $\begin{array}{l}5260 \pm 1265 \\
2965-7200\end{array}$ & $\begin{array}{l}4680 \pm 1260 \\
2.870-6.750\end{array}$ & $\begin{array}{l}4425 \pm 1074 \\
2670-6160\end{array}$ \\
\hline max. force & {$[\mathrm{kN}]$} & $\begin{array}{l}5.6 \pm 0.8 \\
4.4-7.2\end{array}$ & $\begin{array}{l}5.3 \pm 0.75 \\
4.2-6.6\end{array}$ & - & - & - & - \\
\hline
\end{tabular}

Table 1: Summary of mean/standard deviation and minimum/maximum values in the on text of different loading conditions/injury criteria for kicking vertically (VKT CB) with combat boots and kicking horizontally (HKT LS, HKT CB) with light sneakers and combat boots. Results are given for the two groups (Young and Old), respectively.

Figure 4 shows the probability of a fracture as a function of the achieved maximal HIC values. While in the HKT group there is a low probability of a skull fracture, kicks in vertical direction (VKT) result in a medium to high probability of a skull fracture (Table 2 ).

GAMBIT values are found to exceed the generally accepted tolerance level of 1.0 for VKT kicking [11].

\begin{tabular}{|l|l|l|}
\hline AIS Code & Example & Rotational acceleration [rad/s $\left.\mathbf{s}^{2}\right]$ \\
\hline 0 & & \\
\hline 1 & nose fracture & 2878 \\
\hline 2 & $\begin{array}{l}\text { simple, undisplaced vault } \\
\text { fracture }\end{array}$ & 5756 \\
\hline 3 & basilar fracture & 8630 \\
\hline 4 & $\begin{array}{l}\text { complex, open vault } \\
\text { fracture }\end{array}$ & 11511 \\
\hline 5 & major penetrating injury & 14389 \\
\hline
\end{tabular}

Table 2: AIS (Abbreviated Injury Scale) with examples of injuries and thresholds for rotational acceleration [11]

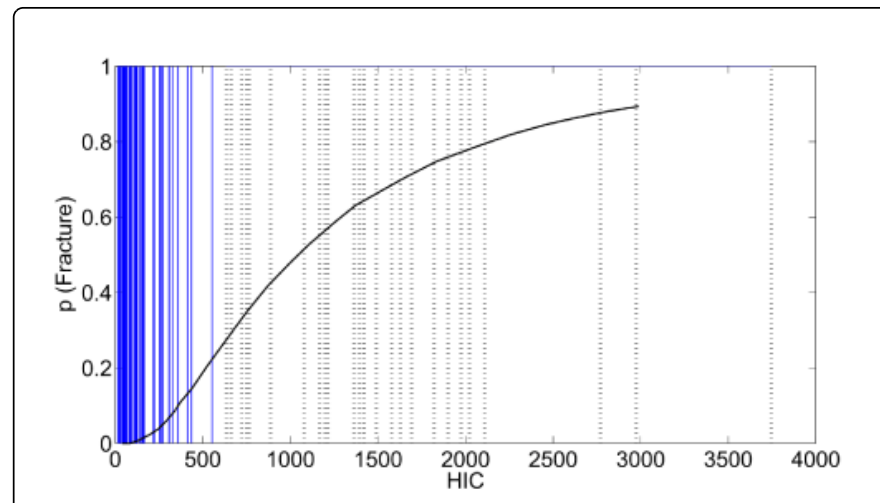

Figure 4: Probability of fracture as a function of HIC (AIS $>=2$ ). Solid Lines are HKT values, dotted lines are VKT values. Graph is based on Hertz et al. [12].

\section{Discussion}

This study analyzed the loading acting on the head examining different kicks and different population groups. In this study no significant influence of age, combat training and shoe type could be found. However, kicking directions revealed a major impact on the result. For all analyses, kicking vertically (VKT) generally means a higher risk for the subject compared to kicking horizontally (HKT). HKT results in lower translational acceleration, but creates higher rotational acceleration values, which may also result in severe brain injuries. Reasons for higher values in the VKT group could be the increased mass due to the use of body weight and a missing "damping" 
Page 5 of 5

effect of the cervical spine - compared to vertical kicks. Also the motion pattern for vertical kicks is easier to perform which may result in an increased impact.

Glißmann reported also a negligible influence of age on the resulting acceleration when applying horizontal kicks [7]. However, he found higher values for active sportsmen compared to unathletic persons - this could be explained by the selection of the test subjects. In our study, only policemen were included who are by profession more trained than the average population [13]. In the same study, Glißmann showed higher accelerations for kicking with working boots compared to soft shoes [8]. This could not be shown in the present study.

The contact forces measured between head and ground where between 4.2 and $7.2 \mathrm{KN}$. Fall tests using cadaver skulls resulted in skull fractures with values between 2 and $6.2 \mathrm{KN}$ [14-17]. Therefore, a high risk of fractures could be determined because of the direct force impact in the VKT group.

In the current study a WordSID dummy was implied. This dummy is also suitable to investigate lateral impacts that are often observed during a kicking attack. In contrast, Glißmann et al. [7] used a Hybrid 3 dummy that captures frontal impacts only.

In this investigation only single force impacts have been taken into account. However, in reality repetitive kicks are not unusual. Repetitions may result in more severe injuries due to further damage mechanisms. E.g. bone may react with micro cracking to single kicks. These cracks could accumulate/accelerate with the next hit which may lead to macroscopic fractures. Similar effects can be expected for soft tissue damage.

This study has several limitations: first of all, only the integral effect of the kicks could be analyzed using established injury criteria. A detailed injury pattern cannot directly be derived from the data mainly because of missing data about the direct contact forces between shoe and head. Furthermore in this context, further detailed analyses of brain injuries are not discussed. As Marjoux et al. [18] pointed out global head accelerations are not useful for the analyses of severe neurological injuries which can only be distinguished with more detailed information.

A certain uncertainty is inherent in the design of the experiments: the test subjects' kicks were very well coordinated, which may not always be the case for the average offender, who might even be on drugs. On the other hand, the offender's mental constitution may lead to a reduced inhibition threshold, which may result in even more serious impacts.

\section{Conclusion}

Even if there are some limitations, the presented data shows the massive potential of injuries associated with head kicks. Irrespective of the offender's age, training state, shoe type and kicking direction major injuries and potential life-threatening consequences can be observed.

\section{Conflict of Interest}

There are no conflicts of interest.

\section{Acknowledgement}

This study has been a part of the project "Wirkung von Fußtritten gegen den Kopf und deren strafrechtliche Relevanz". The authors want to thank the coordinator of the study, Albert Voegeler, Polizeipraesidium Nuremberg, Germany.

\section{References}

1. Bachmann T (2013) Fachsymposium "Wirkung von Fußtritten gegen den Kopf und deren strafrechtliche Relevanz", PKS Sonderauswertung Polizeipräsidium Mittelfranken / Kriminalfachdezernat 1, Vortrag KD Bachmann.

2. Heinke DH (2010) Tottreten: Eine kriminalwissenschaftliche Untersuchung, Pabst, Lengerich UA.

3. Taymoorian U (2000) Rechtsmedizinische Analyse von Todesfällen durch Treten. Dissertation, Berlin, 2000.

4. Bratzke H (1986) "Zur Genese und Morphologie der "traumatischen Hirnruptur"; in Eisenmenger, Wolfgang; Liebhardt, Erich; Schuck, Manfred (Hrsg.): Medizin und Recht: Festschrift für Wolfgang Spann; Berlin, UA".

5. Brinkmann B (2004) Handbuch gerichtliche Medizin I, Heidelberg.

6. Schulz E (1986) Stumpfe und scharfe Gewalt; in Forster, Balduin (Hrsg.): Praxis der Rechtsmedizin für Mediziner und Juristen; Stuttgard, UA.

7. Glißmann C (2002) Wirkung von Fußtritten gegen Kopf und Thorax", Inaugural Dissertation, Medizinische Fakultät, Ernst-Moritz-ArndtUniversität Greifswald, Germeny.

8. Gennarelli TA, Pintar FA, Yoganandan N (2003) Biomechanical Tolerances for Diffuse Brain Injury and a Hypothesis for Genotypic Variability in Response to Trauma. Annual Proc Assoc Adv Automot 47: 624-628.

9. Versace J (1971) A review of severity index, Proc. 15th Stapp Car Crash Conf; SAE.

10. Newman J (1986)A generalized acceleration model for brain injury threshold (GAMBIT)", Proc IRCOBI Conf., pp. 121-131.

11. SAE Safety Test Instrumentation Standards Committee, Revised DEC2003.

12. Hertz (1993) A note on the head injury criterion (HIC) as a predictor of the risk of skull fracture, 37th Annual Procceedings of the AAM.

13. Allsop D (1991)Force deflection and fracture characteristics of the temporoparietal region of the human head, Proc. Intern. Conf. on Biomechanics of Serious Trauma.

14. Allsop D (1988) Facial impact response - a comparison of the Hybrid III dummy and human cadaver, Proc. 32th Stapp Car Crash Conf; SAW.

15. Hodgson V (1971) Breaking strength of the human skull vs. impact surface curvature, Wayne State University School of Medicine, Dept. of Neurosurgery, Report.

16. Schneider D (1972) Impact studies of facial bones and skull, Proc. 16th Stapp Car Crash Conf; SAW 720965, pp. 186-203.

17. Advani S (1975) Human head impact response experimental data and analytical simulations, Proc. Intern. Conf. on Biomechanics of Serious Trauma, pp. 153-162.

18. Marjoux D, Baumgartner D, Deck C, Willinger R (2008) Head injury prediction capability of the HIC, HIP, SIMon and ULP criteria, Accident Analysis \& Prevention 40: 1135-1148. 